\title{
ANALISIS KUALITAS WEBSITE SAMSAT JAMBI MENGGUNAKAN METODE DELONE AND MCLEAN
}

\author{
${ }^{1)}$ Maria Rosario B, ${ }^{2)}$ Marrylintery Istoningtyas, ${ }^{3)}$ Fitria Febrianti \\ ${ }^{1)}$ Sistem Informasi, ${ }^{2)}$ Teknik Informatika, ${ }^{3)}$ Sistem Informasi, Fakultas Ilmu Komputer, Universitas Dinamika \\ Bangsa \\ 1,2,3) J1. Jendral Sudirman Kota Jambi -Jambi - Indonesia \\ E-mail : ${ }^{1)}$ diamar_ros@yahoo.com, ${ }^{2)}$ marrylinterijurnal@gmail.com, ${ }^{3)}$ fitriafebrianti015@gmail.com
}

\begin{abstract}
ABSTRAK
Website SAMSAT merupakan salah satu penerapan teknologi informasi yang digunakan untuk mempermudah pengguna kendaraan bermotor untuk mendapatkan informasi yang berkaitan dengan layanan yang disediakan oleh kantor SAMSAT. Peneliti telah menyebarkan terhadap 50 orang dimana responden $82 \%$ responden menyatakan bahwa website SAMSAT Jambi mempunyai kelemahan diantaranya website tersebut kurang menarik dari segi interface dan terdapat menu yang error. Peneliti menganalisis tingkat kesuksesan website SAMSAT Jambi menggunakan metode Delone dan Mclean Serta Mengetahui pengaruh variabel independen (Kualitas dari sistem, kualitas dari informasi, kualitas terhadapa layanan yang diberikan) terhadap variabel dependen (penggunaan, kepuasan pengguna, manfaat bersih) dengan menggunakan metode SEM dan software SmartPLS. Penelitian ini menghasilkan 7 hipotesis yang diterima dari 9 yang diajukan.
\end{abstract}

Kata Kunci Delone and Mclean, Samsat Jambi, Analisis KualitasWebsite.

\begin{abstract}
The SAMSAT website is an application of information technology that is used to facilitate motorized vehicle users to obtain information related to services provided by the SAMSAT office. The researcher has distributed to 50 respondents, $82 \%$ of the respondents stated that the SAMSAT Jambi website has weaknesses, including the website is less attractive in terms of interface and there is an error menu The researher analyzed the level of success of the website SAMSAT Jambi using the Delone and Mclean method and to determine the effect of independent variables (system quality, information quality, service quality) on the dependent variable (use, user satisfaction, net benefits). Data analysis using SEM and SmartPLS software.Tthe result was found that of the 9 hypotheses proposed in this study, only 7 hypotheses were acceptable.
\end{abstract}

Keyword: Delone and Mclean, Samsat Jambi, Website Quality Analysis.

\section{PENDAHULUAN}

Polri, Dinas Pendapatan provinsi dan PT. Jasa Raharja melakukan kerjasama dalam menerbitkan STNK dan Tanda Nomor Kendaraan Bermotor sehingga dapat dijadikan pemasukan ke kas negara, dimana layanan yang diberikan Pajak Kendaraan Bermotor, Bea Balik Nama Kendaraan Bermotor, dan Sumbangan Wajib Dana Kecelakaan Lalu Lintas Jalan, hal tersebut dinamakan Sistem Administrasi Manunggal Satu Atap (SAMSAT) [1]. Website SAMSAT merupakan salah satu penerapan teknologi informasi yang digunakan untuk mempermudah pengguna kendaraan bermotor untuk mendapatkan informasi yang berkaitan dengan layanan yang disediakan oleh kantor SAMSAT. Informasi yang disajikan dalam website tersebut berupa Info Pemutihan, Data Kendaraan, Pajak Kendaraan, Nilai Jual, Progresif, Whistleblowing System, Standart Pelayanan, serta Pelayanan Publik. Penelitian pertama terhadap 50 orang responden, $82 \%$ responden menyatakan bahwa website SAMSAT Jambi mempunyai kelemahan, $56 \%$ menyatakan bahwa website tersebut kurang menarik dari segi interface, dan $70 \%$ responden menyatakan bahwa terdapat menu yang error dalam website tersebut Selain itu, di dalam website SAMSAT ini belum terdapat menu kolom komentar sebagai sarana penilaian serta penyampaian pendapat oleh pengguna website kepada pihak pengelola website sehingga kualitasnya akan 
semankin meningkat dan memuaskan penggunanya. Peneliti selanjutnya menganalisis kualitas sistem informasi pada website SAMSAT Jambi.

\section{Kerangka Kerja Penelitian}

Peneliti membuat alur kerja penelitian adalah sebagai berikut:

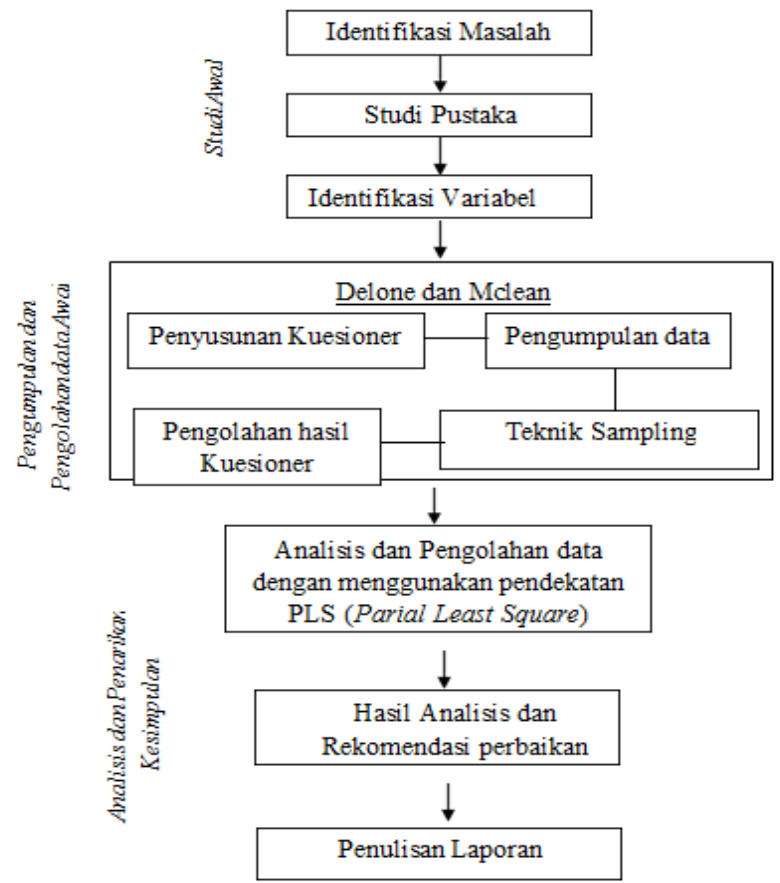

Gambar 1. Kerangka Kerja Penelitian

\section{Hipotesis Penelitian}

Dugaan sementara terhadap rumusan masalah penelitian yakni:

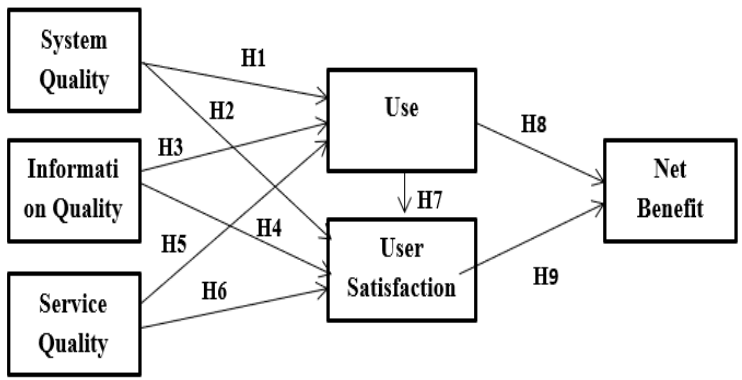

Gambar 2. Hipotesis Penelitian

\section{Indikator Penelitian}

Tabel 1. Indikator Penelitian

\begin{tabular}{|c|c|c|c|}
\hline Var & Indikator & $\begin{array}{l}\text { Kodo } \\
\text { Indik: } \\
\text { ator }\end{array}$ & Sumber \\
\hline \multirow{3}{*}{$\begin{array}{l}\text { Kenalitan } \\
\text { Sintem } \\
(\text { Sysdens } \\
\text { Oroling) }\end{array}$} & $\begin{array}{c}\text { Kemudahan unfuk } \\
\text { digunakan (East } \\
\text { of Cons) }\end{array}$ & $\mathrm{X} 1.1$ & \multirow{3}{*}{$\begin{array}{c}\text { Bahesa } \\
(2018)[3 \\
]\end{array}$} \\
\hline & $\begin{array}{l}\text { Keluandalan } \\
\text { Sisiem dai } \\
\text { (Rditiabifity) }\end{array}$ & $X 1.2$ & \\
\hline & $\begin{array}{l}\text { Kecepatan Akses } \\
\text { (Respoutse Times) }\end{array}$ & $X 1.3$ & \\
\hline \multirow{3}{*}{$\begin{array}{c}\text { Kualitas } \\
\text { Informa } \\
\text { si } \\
\text { (Iryform } \\
\text { arion } \\
\text { Omaling) }\end{array}$} & $\begin{array}{c}\text { Kelengkapan } \\
\text { (Compieterdas) }\end{array}$ & $\times 2.1$ & \multirow{3}{*}{$\begin{array}{c}\text { Saputro } \\
\text { et al } \\
(2016)[4 \\
]\end{array}$} \\
\hline & $\begin{array}{c}\text { Relevan } \\
\text { (Rdildvinde) }\end{array}$ & $\times 2.2$ & \\
\hline & Alvurat (Atewratd) & $\times 2.3$ & \\
\hline \multirow{3}{*}{$\begin{array}{c}\text { Kualitsa } \\
\text { Laysua } \\
\text { m } \\
\text { (Service } \\
\text { Omating) }\end{array}$} & $\begin{array}{c}\text { Janvinas } \\
\text { (Astreresed) }\end{array}$ & X.3.1 & \multirow{3}{*}{$\begin{array}{c}\text { Saputro } \\
\text { et.al } \\
(2016)[4 \\
]\end{array}$} \\
\hline & Fingati (Entpathy) & $\times 3.2$ & \\
\hline & $\begin{array}{c}\text { Responsif } \\
\text { (Resporerivertdsy) }\end{array}$ & $\times 3.3$ & \\
\hline \multirow{3}{*}{$\begin{array}{l}\text { Peaggu } \\
\text { uasu } \\
(C 5 s)\end{array}$} & $\begin{array}{c}\text { Sifat dari } \\
\text { Pengoumam } \\
\text { (Nefurd of Uise) }\end{array}$ & Y'L.1 & \multirow{3}{*}{$\begin{array}{c}\text { Saputro } \\
\text { et.al } \\
(2016)[4 \\
]\end{array}$} \\
\hline & $\begin{array}{c}\text { Prekuensi } \\
\text { Penggurain } \\
\text { (Frdpukssy of wid) }\end{array}$ & Y 1.2 & \\
\hline & $\begin{array}{c}\text { Niat dari } \\
\text { penggunaay } \\
\text { (Itefertion to wede) }\end{array}$ & Y 1.3 & \\
\hline \multirow{3}{*}{$\begin{array}{c}\text { Kepuas } \\
\text { an } \\
\text { Penggu } \\
\text { ua (Crser } \\
\text { Sarigher } \\
\text { ion) }\end{array}$} & $\begin{array}{c}\text { Kepaasan } \\
\text { Leformasi (Ragdat } \\
\text { Visits) }\end{array}$ & $Y 2.1$ & \multirow{3}{*}{$\begin{array}{c}\text { Siregar } \\
(2017)[5 \\
]\end{array}$} \\
\hline & $\begin{array}{c}\text { Kepaasain } \\
\text { Menyeluruh } \\
\text { (Rotodet } \text { Purchese) }\end{array}$ & $Y 2.2$ & \\
\hline & $\begin{array}{c}\text { Keppaasain } \\
\text { (Satiffastion) }\end{array}$ & $Y 2.3$ & \\
\hline \multirow{3}{*}{$\begin{array}{l}\text { Manfaat } \\
\text { Berril } \\
\text { (Net } \\
\text { Bomgfit) }\end{array}$} & $\begin{array}{l}\text { Meningkatkan } \\
\text { Berhaggi } \\
\text { Pengetahuan } \\
\text { (Ineprevidd } \\
\text { Rinewiedge } \\
\text { Sharitg) }\end{array}$ & 21.1 & \multirow{3}{*}{$\begin{array}{l}\text { Siregar } \\
2017)[5]\end{array}$} \\
\hline & 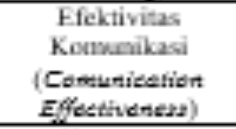 & 21.2 & \\
\hline & $\begin{array}{c}\text { Kegunaan } \\
\text { (Codfulleses) }\end{array}$ & 21.3 & \\
\hline
\end{tabular}

\section{METODE}

1. Penelitian pustaka (Library Research)

Menurut Nazir [6] "Penelitian pustaka merupakan sebuah metode dimana peneliti menggumpulkan dan selanjutnnya mempelajari konsep yang sama dari berbagai sumbersumber yang berasal dari pustaka"

2. Pengamatan (Observation)

"Observasi adalah suatu cara yang dilakukan 
dengan mengamati secara langsung suatu objek penelitian untuk mengumpulkan data yang diperlukan"[7]. Observasi pada penelitian ini dilakukan dengan cara mengamati dan mencoba mengakses secara langsung website SAMSAT Jambi untuk mengetahui menu apa saja yang terdapat dalam website tersebut serta kelemahan-kelmahan yang ada dalam website tersebut.

\section{Kuesioner}

Kuesioner dalam penelitian ini disajikan dalam bentuk sederhana dan ditujukan untuk masyarakat umum dan pengguna/pengunjung website SAMSAT Jambi, dengan ini diharapkan masyarakat umum dan pengguna/pengunjung website SAMSAT Jambi, dimana dengan menggunakan Slovin sampel yang diambil sebanyak 100 responden.

\section{HASIL}

\section{Evaluasi Outer Model (Model Pengukuran)}

Model outer yang diujikan adalah validitas konvergen, validitas diskriminan,

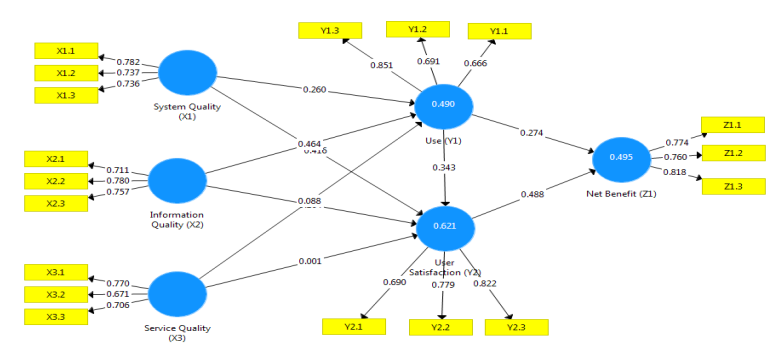

Gambar 2. Model Structural Equation Modelling

\section{Uji Convergent Validity (Outer Loading)}

Tabel 2. Nilai Outer Loading

\begin{tabular}{ccccccc}
\hline Indi. & X1 & X2 & X3 & Y1 & Y2 & Z1 \\
\hline X1.1 & 0.7 & & & & & \\
& 82 & & & & & \\
\hline $\mathrm{X} 1.2$ & 0.7 & & & & & \\
\hline & 37 & & & & & \\
X1.3 & 0.7 & & & & & \\
\hline & 36 & & & & \\
X2.1 & & 0.711 & & & & \\
\hline
\end{tabular}

\begin{tabular}{|c|c|c|c|c|c|}
\hline X2.2 & 0.780 & & & & \\
\hline $\mathrm{X} 2.3$ & 0.757 & & & & \\
\hline X3.1 & & 0.770 & & & \\
\hline X3.2 & & 0.671 & & & \\
\hline X3.3 & & 0.706 & & & \\
\hline Y1.1 & & & 0.851 & & \\
\hline Y1.2 & & & 0.691 & & \\
\hline Y 1.3 & & & 0.666 & & \\
\hline Y2.1 & & & & 0.690 & \\
\hline Y 2.2 & & & & 0.779 & \\
\hline Y 2.3 & & & & 0.822 & \\
\hline Z1.1 & & & & & 0.774 \\
\hline $\mathrm{Z} 1.2$ & & & & & 0.760 \\
\hline $\mathrm{Z} 1.3$ & & & & & 0.818 \\
\hline
\end{tabular}

Uji validitas konvergen dikatakan ideal $(\geq 0,7)$, artinya indikator tersebut valid mengukur konstruk yang dibentuknya [8]. Hasil yang didapat dari uji validitas konvergen sudah dapat diterima karena sudah memenuhi syarat

\section{Uji Discriminant Validity}

Tabel 3. Nilai Discriminant Validity (Cross Loading)

\begin{tabular}{ccccccc}
\hline Indi & $\mathbf{X 1}$ & $\mathbf{X 2}$ & $\mathbf{X 3}$ & $\mathbf{Y 1}$ & $\mathbf{Y 2}$ & $\mathbf{Z 1}$ \\
\hline $\mathrm{X} 1.1$ & $\mathbf{0 . 7 8 2}$ & 0.378 & 0.360 & 0.512 & 0.450 & 0.443 \\
\hline $\mathrm{X} 1.2$ & $\mathbf{0 . 7 3 7}$ & 0.420 & 0.489 & 0.424 & 0.608 & 0.454 \\
\hline $\mathrm{X} 1.3$ & $\mathbf{0 . 7 3 6}$ & 0.365 & 0.464 & 0.287 & 0.487 & 0.377 \\
\hline $\mathrm{X} 2.1$ & 0.379 & $\mathbf{0 . 7 1 1}$ & 0.486 & 0.466 & 0.428 & 0.482 \\
\hline $\mathrm{X} 2.2$ & 0.393 & $\mathbf{0 . 7 8 0}$ & 0.350 & 0.509 & 0.515 & 0.529 \\
\hline $\mathrm{X} 2.3$ & 0.395 & $\mathbf{0 . 7 5 7}$ & 0.489 & 0.485 & 0.408 & 0.512 \\
\hline $\mathrm{X} 3.1$ & 0.468 & 0.488 & $\mathbf{0 . 7 7 0}$ & 0.420 & 0.420 & 0.557 \\
\hline $\mathrm{X} 3.2$ & 0.310 & 0.308 & $\mathbf{0 . 6 7 1}$ & 0.255 & 0.166 & 0.408 \\
\hline $\mathrm{X} 3.3$ & 0.432 & 0.415 & $\mathbf{0 . 7 0 6}$ & 0.377 & 0.431 & 0.429 \\
\hline $\mathrm{Y} 1.1$ & 0.420 & 0.441 & 0.460 & $\mathbf{0 . 6 6 6}$ & 0.422 & 0.515 \\
\hline $\mathrm{Y} 1.2$ & 0.450 & 0.399 & 0.304 & $\mathbf{0 . 6 9 1}$ & 0.473 & 0.278 \\
\hline $\mathrm{Y} 1.3$ & 0.376 & 0.583 & 0.368 & $\mathbf{0 . 8 5 1}$ & 0.603 & 0.523 \\
\hline $\mathrm{Y} 2.1$ & 0.602 & 0.386 & 0.296 & 0.485 & $\mathbf{0 . 6 9 0}$ & 0.378 \\
\hline $\mathrm{Y} 2.2$ & 0.499 & 0.514 & 0.388 & 0.571 & $\mathbf{0 . 7 7 9}$ & 0.598 \\
\hline $\mathrm{Y} 2.3$ & 0.500 & 0.476 & 0.488 & 0.501 & $\mathbf{0 . 8 2 2}$ & 0.553 \\
\hline
\end{tabular}




\begin{tabular}{ccccccc} 
Z1.1 & 0.482 & 0.482 & 0.548 & 0.473 & 0.514 & $\mathbf{0 . 7 7 4 c}$ \\
\hline Z1.2 & 0.443 & 0.509 & 0.601 & 0.431 & 0.508 & $\mathbf{0 . 7 6 0}$ \\
\hline Z1.3 & 0.419 & 0.600 & 0.414 & 0.518 & 0.563 & $\mathbf{0 . 8 1 8}$ \\
\hline
\end{tabular}

Tabel 3 menunjukkan uji discriminant validity sudah dapat terpenuhi.

\section{Uji Average Variance Extracted (AVE)}

AVE digunakan untuk mengukur validitas diskriminan dimana nilai paling kecil sebesar 0,5 memilik hasil yang baik [9]

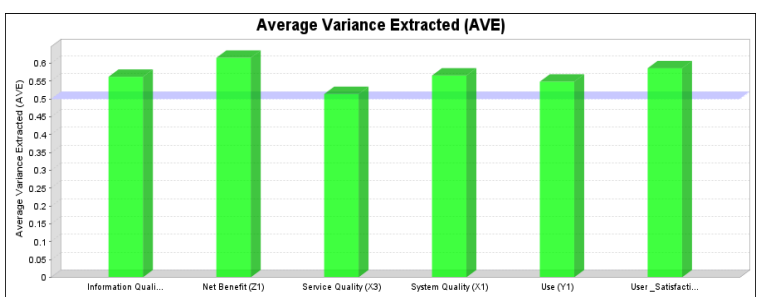

Gambar 4 Diagram Average Variance Extracted (AVE)

Tabel 4 Hasil Nilai AVE

\begin{tabular}{cc}
\hline Variabel (Construct) & $\begin{array}{c}\text { Average Variance } \\
\text { Extracted (AVE) }\end{array}$ \\
\hline System Quality & 0.562 \\
\hline Information Quality & 0.615 \\
\hline Service Quality & 0.514 \\
\hline Use & 0.566 \\
\hline User Satisfaction & 0.549 \\
\hline Net Benefit & 0.586 \\
\hline
\end{tabular}

Berdasarkan gambar dan tabel diatas dapat diketahui nilanya suda memenuhi syarat.

\section{Uji Reliabilitas (Cronbach's Alpha dan Composite Reliability)}

Langkah selanjutnya melakukan pengukuran Cronbach's Alpha

Menurut Haryono[10]'Kesamaan boot dari setiap indikator bukan merupakan asusmsi dari uji komposit reabilitas. Parameter nilai yang baik jika hasil yang diperoleh minimal 0,7 ".

Berikut adalah hasil cronbach's alpha dan

mposite reliability pada penelitian ini:
\begin{tabular}{|l|r|r|}
\hline Information Q... & Cronbach's Alpha & Composite Reliability \\
\hline Net Benefit (Z1) & 0.611 & 0.794 \\
\hline Service Quality ... & 0.688 & 0.828 \\
\hline System Quality... & 0.551 & 0.760 \\
\hline Use (Y1) & 0.620 & 0.796 \\
\hline User_Satisfacti... & 0.582 & 0.783 \\
\hline
\end{tabular}

Gambar 5 Hasil uji Cronbach's Alpha dan Composite Reliability

Gambar diatas menunjukkan bahwa nilai Composite Reliability untuk semua variabel yang diteliti memenuhi syarat sedangkan untuk pengujian Cronbach's Alpha hasilnya tidak baik.

\section{Evaluasi Inner Model (Model Struktural)}

Pengujian Inner Model (model struktural) yang terdiri atas:

\section{Uji $R$-Square $\left(\mathbf{R}^{2}\right)$}

Digunakan untuk mengetahui hubungan dari beberapa variable yang digunakan maka diperlukan Uji $R$-Square dimana prediksi yang baik dari sebuah model akan didapat apabila nilai $\mathrm{R}^{2}$ semakin tinggi [8]

\begin{tabular}{|c|c|c|}
\hline & R Square & R Square Adjus... \\
\hline Net Benefit (Z1) & 0.495 & 0.484 \\
\hline Use (Y1) & 0.490 & 0.474 \\
\hline User_Satisfacti... & 0.621 & 0.605 \\
\hline
\end{tabular}

\section{Gambar 6 Nilai $R$-Square}

Manfaat bersih yang diperoleh sebesar 0,495 dapat moderate/sedang, sedangkan variabel penggunaan adalah sebesar 0,490 dapat dikatakan pengaruhnya moderate/sedang. Untuk variabel kepuasan pengguna yakni sebesar 0,621 dapat dikatakan pengaruhnya moderate/sedang. 
Uji F-Square (F2)

Uji F-Square nilai yang baik jika hasil yang diperoleh kecil dan dapat digunakan untuk mengetahui bagaimana pengaruh variabel laten eksogen atau independen terhadap variabel laten endogen atau dependen.

Hasil uji F-Square adalah:

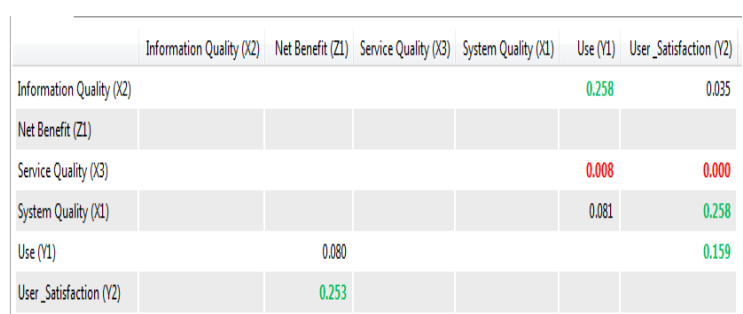

Gambar 7 Nilai $F$-Square

Adapun kesimpulan hasilnya adalah sebagai berikut:

1. Variabel yang tidak memiiliki pengaruh dengan variable lainnya adalah manfaat bersih, Kualitas Layanan terhadap Kepuasan Pengguna

2. Variable yang memiliki pengaruh kecil adalah Kualitas Informasi terhadap kepuasan pengguna, Kualitas Layanan terhadap Penggunaan, Kualitas Sistem terhadap Penggunaan, Penggunaan terhadap Manfaat Bersih.

3. Variabel yang memiliki pengaruh sedang/moderat adalah Kualitas Informasi terhadap Penggunaan, Penggunaan terhadap Kepuasan Pengguna, Kepuasan Pengguna terhadap Manfaat Bersih.

4. Tidak ada variabel yang memiliki pengaruh besar.

\section{Hasil Bootsraping}

Hasil Bootstraping adalah sebagai berikut:

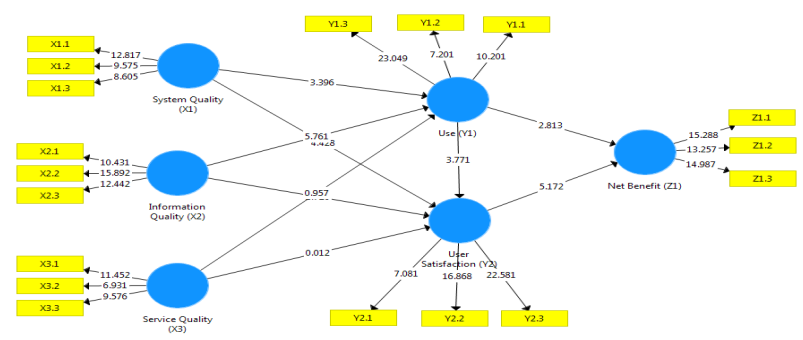

Gambar 8 Model Struktural Bootstraping

Berdasarkan hasil perhitungan bootsraping diatas, dilakukan untuk melihat signifikansi hubungan antar konstrak yang ditunjukkan oleh nilai T Statistics. T Statistics dikatakan valid apabila antar variabel memiliki nilai T Statistics $\geq 1,96$ [11]. Indikator juga dapat table nilai t-statistik antara variable independen ke variable dependen dalam table pengaruh langsung (path coefficient) pada output smartpls dibawah ini:

Tabel 5. Uji Hipotesis (Path Coefficients)

\begin{tabular}{|c|c|c|c|c|c|}
\hline & $\begin{array}{l}\text { Origin } \\
\text { al } \\
\text { Sampl } \\
\text { e }\end{array}$ & $\begin{array}{l}\text { Samp } \\
\text { le } \\
\text { Mean }\end{array}$ & $\begin{array}{l}\text { Standar } \\
\text { d } \\
\text { Deviati } \\
\text { on }\end{array}$ & $\begin{array}{l}\mathrm{T} \\
\text { Statisti } \\
\mathrm{cs}\end{array}$ & $\begin{array}{l}\mathrm{P} \\
\text { Value } \\
\mathrm{S}\end{array}$ \\
\hline $\mathrm{X} 1 \rightarrow \mathrm{Y} 1$ & 0.260 & 0.253 & 0.077 & 3.396 & 0.001 \\
\hline $\mathrm{X} 1 \rightarrow \mathrm{Y} 2$ & 0.505 & 0.500 & 0.091 & 5.542 & 0.000 \\
\hline $\mathrm{X} 2 \rightarrow \mathrm{Y} 1$ & 0.464 & 0.458 & 0.080 & 5.761 & 0.000 \\
\hline $\mathrm{X} 2 \rightarrow \mathrm{Y} 2$ & 0.323 & 0.311 & 0.095 & 3.388 & 0.001 \\
\hline $\mathrm{X} 3 \rightarrow \mathrm{Y} 1$ & 0.088 & 0.106 & 0.092 & 0.957 & 0.339 \\
\hline $\mathrm{X} 3 \rightarrow \mathrm{Y} 2$ & 0.031 & 0.050 & 0.090 & 0.350 & 0.726 \\
\hline $\mathrm{Y} 1 \rightarrow \mathrm{Y} 2$ & 0.343 & 0.338 & 0.091 & 3.771 & 0.000 \\
\hline $\mathrm{Y} 1 \rightarrow \mathrm{Z} 1$ & 0.442 & 0.442 & 0.081 & 5.468 & 0.000 \\
\hline $\mathrm{Y} 2 \rightarrow \mathrm{Z} 1$ & 0.488 & 0.489 & 0.094 & 5.172 & 0.000 \\
\hline
\end{tabular}

Dari tabel diatas dapat disimpulkan bahwa terdapat 7 hipotesis yang diterima yaitu hipotesis $1,2,3,4,7,8$, dan 9 serta terdapat 2 hipotesis yang ditolak yaitu hipotesis 5 dan 6 [8]

\section{Rekomendasi berdasarkan variable service quality terhadap use dan Usersatisfaction}

Dianjurkan website SAMSAT Jambi memiliki respon yang cepat dari pengembang jika sistem informasi mengalami masalah, menyediakan 
menu kolom komentar yang berguna untuk pengguna website jambi untuk memberikan feedback terhadap kualitas website SAMSAT Jambi serta diharapkan pengembang dapat memperbaiki beberapa menu yang masih error atau kosong untuk meningkatkan kepuasan pengguna website SAMSAT Jambi dan agar menjadikan website SAMSAT Jambi ini menjadi lebih baik lagi.

\section{KESIMPULAN}

Kesimpulan yang didapat dari penelitian ini adalah:

1. Penelitian ini menggunakan 6 variabel yang terdiri dari variablebebas information quality, system quality, service quality dan variabel terikat use, user satisfaction, and net benefit sesuai dengan metode Delone and Mclean. Untuk mengetahui tingkat kesuksesan website SAMSAT Jambi ini peneliti telah menyebarkan kuesioner/angket kepada pengguna website SAMSAT Jambi yang mana telah terkumpul sebanyak 100 responden sebagai sampel dalam penelitian ini, kemudian hasil kuesioner tersebut diolah menggunakan software smartPLS serta dilakukan analisis SEM untuk melakukan uji serta mengetahui tingkat kesuksesan website SAMSAT Jambi ini

2. Hanya 7 hipotesis yang dapat diterima yaitu:

variabel system quality berpengaruh positif terhadap variable use, variabel system quality berpengaruh positif terhadap variable user satisfaction, variabel information quality berpengaruh positif terhadap variable use, variabel information quality berpengaruh positif terhadap variable user satisfaction, variabel use berpengaruh positif terhadap variabel user satisfaction, variabel use berpengaruh positif terhadap variable net benefit dan variabel user satisfaction berpengaruh positif terhadap variable net benefit

3. Kualitas layanan tidak mempunyai pengaruh yang signifikan terhadap kepuasan pengguna hubungan tersebut berdasarkan indikator dalam kuesioner dengan topik pertanyaan dan masukan responden yaitu pengguna merasa aman dalam mengakses atau mengirim data melalui sistem pada website SAMSAT Jambi, Sistem memberikan beberapa masukan yang mungkin berguna bagi pengguna, serta Sistem memberikan tanggapan sesuai dengan apa yang di lakukan pengguna Indikator tersebut tidak mampu memberikan kepercayaan responden dalam meningkatkan signifikansi terhadap uji hipotesis ini yang berarti kualitas sistem perku ditingkatkan lagi untuk meningkatkan jumlah pengguna website SAMSAT Jambi

4. Kualitas layanan tidak mempunyai pengaruh yang signifikan terhadap kepuasan pengguna hubungan tersebut berdasarkan indikator dalam kuesioner dengan topik pertanyaan dan masukan responden yaitu pengguna merasa aman dalam mengakses atau mengirim data melalui sistem pada website SAMSAT Jambi, Sistem memberikan beberapa masukan yang mungkin berguna bagi pengguna, serta Sistem memberikan tanggapan sesuai dengan apa yang di lakukan pengguna Indikator tersebut tidak mampu memberikan kepercayaan responden dalam meningkatkan signifikansi terhadap uji hipotesis ini. 


\section{DAFTAR PUSTAKA}

[1] F. N. Zaenal Mustofa, "Inovasi Pelayanan Pembayaran Pajak Kendaraan Bermotor Melalui Layanan Samsat Mini ( Samin ) Di Kantor Bersama Samsat Kabupaten Bojonegoro," J. Publika, vol. 5, no. 1, hal. 1-8, 2017. [Diakses: 2 Oktober 2019].

[2] D. Mardiana, G. Testiana, and M. Kadafi, "PROSIDING seminar nasional sisfotek Penerapan Model Delone dan Mclean Pengukuran Kesuksesan Simak Online UIN Raden Fatah Palembang," Penerapan Model Delone dan Mclean Pengukuran Kesuksesan Simak Online UIN Raden Fatah Palembang Dwi, vol. 3584, hal. 47-56, 2017. [Diakses: 5 Desember 2019].

[3] B. P. Bahesa, "Analisis Kesuksesan Sistem Informasi Website Pemerintah Kabupaten Pamekasan Berdasarkan Model Delone and McLean." hal. 1-109, 2018. [Diakses: 12 Desember 2019].

[4] P. H. Saputro, D. Budiyanto, and J. Santoso, "Model Delone and Mclean Untuk Mengukur Kesuksesan EGovernment Kota Pekalongan," Sci. J. Informatics, vol. 2, no. 1, hal. 1-8, 2016, doi: 10.15294/sji.v2i1.4523. [Diakses: 5 Januari 2020].

[5] D. Y. Siregar, "Pengukuran Kesuksesan Sistem Informasi Keuangan Universitas Atma Jaya Yogyakarta Dengan Model Delone Dan Mclean," hal 18-36, 2017. [Diakses: 16 Januari 2021].

[6] Moh. Nazir, "Metode Penelitian," Metod. Penelit., 2014.

[7] D. P. Anggraeni, "Pelanggan ( Survei pada Pelanggan Nasi Rawon di Rumah Makan Sakinah Kota Pasuruan )," vol. 37, no. 1. [Diakses: 16 Januari 2020].

[8] W. Abdillah and J. Hartono, "Pengaruh
Motivasi Kerja Terhadap Kinerja Karyawan Melalui Kepuasan Kerja Sebagai Variabel Mediasi Pada Karyawan Pt . Borwita Citra Prima Surabaya," Agora, 2017. [Diakses: 16 Januari 2020].

[9] W. Abdillah and H. Jogiyanto, "Partial Least Square (PLS) Alternatif Structural Equation Modeling (SEM) dalam Penelitian Bisnis," in book, 2015. [Diakses: 17 Januari 2020.

[10] S. Hudananta, T. Haryono, and Sarjiya, "Study of overcurrent protection on distribution network with distributed generation: An Indonesian case," in Proceedings - 2017 International Seminar on Application for Technology of Information and Communication: Empowering Technology for a Better Human Life, iSemantic 2017.[Diakses: 17 Januari 2020].

[11] W. Abdillah and J. Hartono, "Pengaruh Motivasi Kerja Terhadap Kinerja Karyawan Melalui Kepuasan Kerja Sebagai Variabel Mediasi Pada Karyawan Pt . Borwita Citra Prima Surabaya," Agora, 2017. 